egiment was out in small detachments at various outposts in the country, where the facilities for contracting venereal disease were limited. Occasionally, for regimental purposes, these detachments came into town, comparatively free from disease, but in a short time numbers of them contracted it from some of the prostitutes of the town, and before long it increased amongrst these prostitutes and therefore amongst the male civilian population of the town. In another sense, men, I am sorry to say, are more guilty than women. In your leader of Oct. 20 th you say "the experience of Lock Hospital and visiting surgeons is that these women may infect an almost unlimited number of men before they themselves are aware that they have anything the matter with them." (This is what I pointed out to the select committee before referred to.) But this can hardly be the case with males; anyone who has had even a little experience of ordinary practice knows how fidgety and nervous nearly all men are about the slighest abrasion of the penis, and it must be rare indeel that a man has venereal disease and does not know it; yet they deliberately have connexion with women and infect them. In the passage I have already quoted from THE LANCET of Sept. 15th, you say that the Acts are directed "against a proportion of the female sex who make a trade of prostitution." Here the knife cuts both ways. Before there can be any trade, there must be buyers and sellers; both buyers and sellers are trading, and both are equally concelned in every transaction in which they participate. While the producer has no right to serve an injurious article, neither has the consumer any right to injure the producer in taking possession of his wares; therefore the man who infects a female is equally culpable with the female who infects a nan.

It would take up too much of your valuable space at present for me to suggest amendments to the present Acts. My object in writing now is rather to show that there is no attempt made at present by these Acts to modify a most important factor in the causation and spread of venereal disease. I am, Sirs, yours faithfully,

Cambridge, Oct. 25th, 1888 . JoHN Ross, M.B.

\section{MENSTRUATION AFTER ENTIRE REMOVAL OF BOTH OVARIES.}

To the Editors of THE LANCET.

SIRs,-I was unfortunately not able to attend the last meeting of the Medical and Chirurgical Society (Oct. 23rd), but should much like to make some comment on a particular point raiseil. Mr. Knowsley Thornton is thus reported :"It was interesting to him to find that Mr. Meredith held the view that when both ovaries were entirely removed no recurrence of menstruation could occur. That had always been his own experience, though he admitted that what seemed an extremely trifling remmant of ovary, if left behind, might learl to serious results." I have no doubt that in the vast majority of instances the above statement holds good; but there are exceptions, for in one of my ovariotomies I was obliged entirely to remove both organs, and will give a very brief account of the case and of the subsequent event.

An unmarried woman, aged twenty-four, was in the beginning of this year placed under ny care by Dr. Pollock. On Feb. 3rd I performed ovariotomy, and, finding the other ovary also diseased, removed it likewise. The patient had neither pain nor fever, indeed, she recovered with less difficulty than often follows a quite trivial injury, leaving ny immediate care in three weeks, and going into the country. The interest of the case centres, however, on the events subsequent to the entire removal of both ovaries. At the operation I took away on the left side the whole of the cystic ovary, together with the greater part of the Fallopian tube and pampiniform plexus, which were spread out upon the cyst wall. On the right side the ovary was nearly double its normal size, very hard and fibrous; it was much altered in form, being alnost kidney shaped, with the long axis directed obliquely upwards and inwards; the ligament being attachel to what would represent the hilus. This ligament and the vessels were tied and serered quite three-quarters of an inch inside the gland. I am quite certain, as also is Mr. Sheild, who most kindly and ably assisted me, that not the minutest part of the orary was left behind. Menstruation remained absent, although in April she complained of "flushings" and pain in the back until the middle of June, when a very slight catamenial discharge appeared. A month later, and every month since, she has menstruated regularly, "just as she used to do before the operation."

I am, Sirs, your obedient servant

Wimpole-street, Oct. 29th, 1888 . RICHARD BARWELT.

\section{THE ILLNESS OF THE IAATE GERMAN EMPEROR. \\ To the Editors of THE LANCET.}

Sins,-Sir Morell Mackenzie at the end of his pamphlet gives a list of twenty-two cases of cancer for which thyrotomy was performed. I operated upon one of these cases in 1872, when I was surgeon at the Golden-square Throat Hospital. Tracheotomy had been done seven months' previously for difficulty of breathing by a Halifax surgeon. At the time I operated the larynx was filled with carcinomatous growths, the left ary-epiglottic fold was thickened, and the voice was completely lost. No com parison can be made between the case of the late German Emperor and mine, for the German surgeons proposed thyrotomy when there was only a very small growth on the left vocal cord, and the voice was slightly affected. I am aware that in other cases of Dr. Mackenzie's table the disease was far advanced, and therefore the deductions he has had drawn from it as to the fatality attending the operation of thyrotomy are unreliable.

Canterbury, Nov. 5th, 1888 I am, Sirs, yours faithfully,

\section{ON THE TREATMENT OF PUERPERAL SEPTICAMIA.}

To the Editors of THE LANCET.

Srrs,-May I plead the importance of the subject as an excuse for asking to be allowed a few words of explanation, as I fear that in trying to be brief I have failed to be clear. In the first place, I am quite ready to admit the value of vaginal injections, and I constantly employ them myself. What I wanted to say was that I look upon them as useless in "such cases" - i.e., those in which the uterine cavity is the seat of the trouble; and especially to emphasise the importance of settling this question as early as possible, seeing how rapidly septic material increases. I think the treatment carried out by Dr. McBean admirably adapted to meet the conditions existing at that moment when, of course, mere douching would have been useless; but I venture to believe it possible that if the syringe had been efficiently used some days earlier that treatment might not have been required.

I am, Sirs, your obedient servant,

Lewisham, Nov. 1st, 1888 .

Francis T. TAYler.

\section{BIRMINGHAM. \\ (From our own Correspondent.)}

FUNERAL AND BURIAL REFORM.

The Church of England Burial, Funeral, and Mourning Reform Association exhibits a comprehensive title for its aims. To all sensible people there is much to be done in this direction, and the fact of calling attention to many of the abuses in connexion with the subject will awaken inquiry and be likely to ensure some degree of reform. The chief object of a meeting lately held here under these auspices was to memorialise Governnent for the purpose of sanctioning a more rational and sanitary method of interment. It was pointed out that brick graves and durable coffins retard the process of decay, and promote the generation of noxious cases, which in crowded districts are most injurious to the living. Cremation was strongly advocated, as being the most scientific method of dealing with the dead; while the sentiment embodied in wreaths, and the traditions of feasting among the poor, were made the marks of adverse criticism by various speakers.

INFANT MORTALITY.

"It is the invariable practice to let illegitimate children die." Such were the startling words uttered by a high 